УДК 612.172:176:612.67:615.272

DOI: 10.37621/JNAMSU-2021-1-1

«Журнал НАМН України» | 2021 | т. 27| № 1| С. 5-11

\section{Вплив комбінації}

АТФ-АОНГ

і молсиАОміну

на біоелектричну

активність міокарда

молодих і старих

щурів за умов

хронічного м'якого<smiles>[GeH2]=[GeH2]</smiles>

\section{Л. П. Купраш , Л.Б.Шарабура, \\ Т. М. Пантелеймонова, \\ С. О. Гударенко, Н. В. Сикало, \\ В. В. Безруков}

ДУ «Інститут геронтологіi

ім. Д. Ф. Чеботарьова НАМН Украӥни», вул. Вишгородська, 67, Київ 04114, Україна

Вступ. Вікові зміни серцево-судинної системи обумовлюють зниження іiі резервних адаптаційних можливостей та підвищення ймовірності розвитку захворювань в умовах стресу та навантаження. В ряді досліджень доведена значна роль емоційного перенавантаження та стресів у розвитку серцево-судинних захворювань. Високий рівень захворюваності системи кровообігу, тривалий перебіг і тяжкість захворювань у людей похилого та старечого віку визначають актуальність пошуку ефективних і безпечних лікарських засобів.

Мета роботи: вивчити вплив комбінації АТФ-ЛОНГ і молсидоміну на функціональний стан міокарда молодих і старих щурів в умовах хронічного м'якого стресу.

Матеріали та методи. У дослідах на молодих (10 міс.) і старих (24 міс.) щурах-самцях лінії Wistar досліджена кардіотропна і кардіопротекторна активність комбінації метаболічного кардіопротектора АТФ-ЛОНГ і судинорозширювального засобу молсидоміну в умовах хронічного м'якого стресу.
Influence

of ATP-LONG

and molsidomine

combination

on the bioelectric

activity

of the myocardial

of young and old rats

in chronic soft stress

\section{Liana P. Kuprash , Ludmila B. Sharabura, Tetyana M. Panteleymonova, Svitlana O. Hudarenko, Nina V. Sykalo, Vladislav V. Bezrukov}

State Institution "D. F. Chebotarev Institute of Gerontology of the NAMS of Ukraine", Vyshgorodska Street, 67, Kyiv 04114, Ukraine

Introduction. Age-related changes in the cardiovascular system lead to a decrease in its reserve adaptive capabilities and an increase in the likelihood of developing diseases under stress and overstrain. A number of experiments have proven the significant role of emotional overstrain and stress in the development of cardiovascular diseases. The high incidence of the circulatory system, the long course and severity of diseases in elderly and old people determine the relevance of the search for treatment using effective and safe drugs.

Aim: investigate the effect of a combination of ATP-LONG and molsidomine on the functional state of the myocardium of young and old rats under chronic soft stress.

Materials and methods. In experiments on young (10 months) and old (24 months) male Wistar rats, the cardiotropic and cardioprotective activity of the combination of the metabolic cardioprotector ATP-LONG and the vasodilator molsidomine was studied under conditions of chronic soft stress. 
Результати. У молодих щурів встановлена негативна дія хронічного м'якого стресу на біоелектричну активність міокарда - порушення процесів реполяризації, проведення $\mathrm{i}$ скоротливості серця. Введення комбінації АТФ-ЛОНГ і молсидоміну нормалізувало показники біоелектричної активності міокарда та підвищувало його стійкість до дії стресувальних факторів. У старих щурів під дією хронічного стресу ознаки порушення реполяризації та електричної нестабільності серця були більш значними в порівнянні з молодими тваринами. Застосування комбінації АТФ-ЛОНГ і молсидоміну запобігало ушкоджувальному впливу хронічного стресу та сприяло нормалізації електрофізіологічних параметрів міокарда старих щурів.

Висновки. Результати експериментальних досліджень свідчать про фармакологічну кардіотропну активність комбінації АТФЛОНГ і молсидоміну в молодих і старих щурів в умовах хронічного м'якого стресу.

Ключові слова: молоді щури, старі щури, хронічний м'який стрес, міокард, електрокардіограма, біоелектрична активність серця, АТФ-ЛОНГ, молсидомін, кардіопротекторна дія.

Для цитування: Купраш ЛП, Шарабура ЛБ, Пантелеймонова ТМ, Гударенко СО, Сикало НВ, Безруков ВВ. Вплив комбінації АТФ-ЛОНГ і молсидоміну на біоелектричну активність міокарда молодих $i$ старих щурів за умов хронічного м'якого стресу. Журнал Національної академії медичних наук України. 2021;27(1):5-11. DOI: 10.37621/JNAMSU-2021-1-1.

\section{ВІДОМОСТІ ПРО АВТОРІВ}

Купраш Ліана Петрівна - д. м. н., завідувачка лабораторії геріатричної фармакологіiі, ORCID:0000-0001-8196-751X;

Шарабура Людмила Борисівна - К. б. н., провідний науковий співробітник лабораторії геріатричної фармакології, ORCID: 0000-0002-8182-7979;

Пантелеймонова Тетяна Миколаївна - к. б. н., провідний науковий співробітник лабораторії геріатричної фармакології, ORCID: 0000-0002-3606-5805

Гударенко Світлана Олексіївна - науковий співробітник лабораторії геріатричної фармакології, ORCID: 0000-0002-3612-5484;

Сикало Ніна Володимирівна - к. б. н., провідний науковий співробітник лабораторії фізіології, ORCID: 0000-0001-7812-8504;

Безруков Владислав Вікторович - д. м. Н., проф., акад. НАМН України, завідувач лабораторії фізіології, директор Інституту, ORCID:0000-0002-3913-3818.
Results. The negative impact of chronic soft stress on the bioelectrical activity of the myocardium - a violation of the processes of repolarization, conduction and contractility of the heart was found in young rats. The combination of ATP-LONG and molsidomine normalized the bioelectrical activity of the myocardium and increased its resistance to stress factors. In old rats under the influence of chronic stress, signs of impaired repolarization and electrical instability of the heart were more significant than in young animals. The combination ATP-LONG and molsidomine prevented the damaging effect of chronic stress and contributed to the normalization of the electrophysiological parameters of the myocardium of old rats.

Conclusions. The results of experiments indicate the pharmacological cardiotropic activity of the combination of ATPLONG and molsidomine in young and old rats with chronic soft stress.

Keywords: young rats, old rats, chronic soft stress, myocardium, electrocardiogram, bioelectrical activity of the heart, ATP-LONG, molsidomine, cardioprotective effect.

For citation: Kuprash LP, Sharabura LB, Panteleymonova TM, Hudarenko SO, Sykalo NV, Bezrukov VV. Influence of ATP-LONG and Molsidomine combination on the bioelectric activity of the myocardial of young and old rats in chronic soft stress. Journal of the National Academy of Medical Sciences of Ukraine. 2021;27(1):5-11. DOI: 10.37621/JNAMSU-2021-1-1.

The article was received on 22.12 .2020

For review 24.02.2021

Accepted for publication on 28.04.2021

\section{INFORMATION ABOUT AUTHORS}

Liana P. Kuprash - Dr. Sci. (Medicine), Head of the Geriatric Pharmacology Laboratory, ORCID: 0000-0001-8196-751X;

Ludmila B. Sharabura - Cand. Sci. (Biology), Leading Researcher of the Geriatric Pharmacology Laboratory, ORCID:0000-0002-8182-7979;

Tetyana M. Panteleymonova - Cand. Sci. (Biology), Leading Researcher of the Geriatric Pharmacology Laboratory, ORCID:0000-0002-3606-5805;

Svitlana O. Hudarenko - Researcher of the Geriatric Pharmacology Laboratory, ORCID: 0000-0002-3612-5484;

Nina V. Sykalo - Cand. Sci. (Biology), Leading Researcher of the Physiology Laboratory, ORCID: 0000-0001-7812-8504;

Vladislav V. Bezrukov - Dr. Sci. (Medicine), Prof., Full Member of the NAMS of Ukraine, Head of the Physiology Laboratory, Director of the State Institution, ORCID: 0000-0002-3913-3818.

\author{
Liana P. Kuprash \\ ORCID:0000-0001-8196-751X \\ kuprash@geront.kiev.ua
}




\section{ВСТУП}

В структурі захворювань людей похилого і старечого віку провідне місце займає патологія серцево-судинної системи. Вікові зміни серцево-судинної системи обумовлюють зниження іï резервних адаптаційних можливостей та підвищення ймовірності розвитку захворювань $[1,2]$.

У розвитку серцево-судинних захворювань значна роль належить емоційним перенавантаженням та стресам. Згідно з результатами численних клінічних спостережень і експериментальних робіт серцево-судинна система $€$ основною мішенню стресової реакції. Стресове пошкодження міокарда і кровоносних судин становить основу патогенезу атеросклерозу, тромбозу судин, коронароспазму, міокардіодистрофіі, інфаркту міокарда та артеріальної гіпертензії [3-5].

Серед патофізіологічних механізмів впливу хронічного стресу на виникнення та наслідки серцево-судинних захворювань слід відзначити роль надмірної активації симпатичного відділу вегетативної нервової системи, зниження продукції оксиду азоту, підвищення секреції глюкокортикоїдів, порушення мозкової мікроциркуляції та активації процесів тромбоутворення [6-8].

При хронічному стресі в результаті тривалого впливу подразників виснажуються механізми адаптації й адаптивні реакції перетворюються на патогенні, викликають суттєві структурні та функціональні порушення в органах і системах організму [9-15]. Під дією хронічного стресу в серцево-судинній системі порушуються процеси збудження, проведення і скоротливості міокарда. Стрес викликає зміни серцевого ритму (тахікардія й брадикардія), порушення внутрішньопередсердної та внутрішньошлуночкової провідності [9-15].

Патогенна дія тривалого стресу на серце значно вища у похилому і старечому віці, ніж у молодих людей. Це обумовлене віковими змінами енергопостачання, порушеннями електролітного обміну, змінами нейроендокринної регуляції (зниження стійкості міокарда до катехоламінів, підвищення симпатичної активності на тлі парасимпатичного і барорефлекторного впливу) і погіршенням коронарного кровотоку $[3,16]$.

Високий рівень захворюваності системи кровообігу, тривалий перебіг і тяжкість захворювань у людей похилого та старечого віку визначають необхідність оптимізації ї лікування з використанням ефективних і безпечних лікарських засобів. Перспективним в цьому плані $€$ використання препаратів метаболічної дії, які сприятливо впливають на метаболізм і енергетичний обмін кардіоміоцитів, покращують судинний тонус і кровопостачання міокарда, підвищують його скорочувальну функцію. Доведено, що метаболічна терапія усуває порушення клітинного метаболізму, іонного гомеостазу та функцій мембран кардіоміоцитів, запобігає розвитку незворотних процесів у міокарді. На сьогодні метаболічна терапія зайняла чільне місце в схемах лікування серцево-судинної патології та включена до міжнародних рекомендацій [17-19].

До препаратів метаболічної дії належить АТФ-ЛОНГ різнолігандна координаційна сполука, молекула якої включає АТФ, іони калію і магнію та гістидин, взаємодія яких зумовлює фармакологічну активність препарату. В результаті комплексної дії компонентів АТФ-ЛОНГ покращує коронарний кровообіг, підвищує скорочувальну функцію серця, оптимізує функціональний стан лівого шлуночка та серцевий викид [20-23].

Особливої уваги заслуговують комбіновані препарати, комплексна дія яких дозволяє підвищити ефективність лікування та зменшити побічну дію фармакотерапії. Значний інтерес становить комбінація АТФ-ЛОНГ з судинорозширювальними засобами, зокрема, нітратами. Серед них перспективним $є$ молсидомін - вазодилататор з групи сиднонімінів, який, на відміну від органічних нітратів, не індукує розвиток толерантності й може використовуватися протягом тривалого часу [24].

Молсидомін в процесі метаболізму виділяє оксид азоту (NO), який, стимулюючи гуанілциклазу, підвищує вміст внутрішньоклітинного циклічного гуанозинмонофосфату в міоцитах судин, що призводить до релаксації судинної стінки та вазодилатації $[25,26]$.

В умовах характерного для стресу дефіциту оксиду азоту, введення донатора NO - молсидоміну сприяє нормалізації процесів метаболізму в міокарді $[27,28]$.

Комбінація метаболічного кардіопротектора АТФ-ЛОНГ і судинорозширювального засобу молсидоміну може бути перспективним засобом лікування захворювань серцевосудинної системи у хворих похилого і старечого віку.

Метою дослідження було вивчення впливу комбінації АТФ-ЛОНГ і молсидоміну на функціональний стан міокарда молодих і старих щурів в умовах хронічного стресу.

\section{МАТЕРІАЛИ ТА МЕТОДИ}

Дослідження проведені на молодих (6 міс.) і старих (26 міс.) щурах-самцях лінії Wistar, кожні з яких були розподілені на окремі 3 групи: інтактну, контрольну (хронічний стрес) та дослідну (на тлі хронічного стресу тварини отримували комбінацію АТФ-ЛОНГ і молсидоміну). В кожній групі утримувалось по 8 (молодих) або 6 (старих) щурів.

Хронічний м'який стрес викликали за методом P. Willner [29], адаптованим до умов досліду А. Крупіною і співавт. [30]. Суть методу полягає у тому, що протягом 8 тижнів щурів щоденно піддають дії м'якого стресогенного подразника у непередбачуваній для тварини послідовності, з 7-денним інтервалом зміни подразника (тісна, брудна або нахилена клітка; харчова або питна депривація; неприємний запах; штучне освітлення вночі).

Досліджуваний препарат - фіксована фармакологічна комбінація, що включає АТФ (у формі АТФ-лонг - різнолігандної координаційної сполуки) і молсидомін - застосовували із розрахунку молсидоміну 2 мг на кг маси тіла, АТФ-ЛОНГ - 10 мг на кг маси тіла, сублінгвально, протягом 14 діб (7-8-й тижні досліду). Після завершення курсу лікування оцінювали біоелектричну активність міокарда у фіксованих на спині тварин за даними електрокардіограм, записаних за допомогою електрокардіографа ЕК1Т-1 («Аксион», Росія) в ІІ відведенні.

При проведенні досліджень були дотримані «Правила проведення досліджень з використанням експериментальних тварин» та правила ДУ «Інститут геронтології 
ім. Д. Ф. Чеботарьова НАМН України» щодо утримання та використання лабораторних тварин.

\section{РЕЗУЛЬТАТИ ТА ОБГОВОРЕННЯ}

При аналізі електрокардіограм молодих щурів, що знаходилися під дією хронічного стресу (контрольна група), встановлене порушення ритму серця (брадикардія, тахікардія та екстрасистолія) і провідності (подовження інтервалу QR і розширення комплексу QRS). Поряд з цим відмічається зменшення амплітуди зубця $\mathrm{R}$, депресія або інверсія зубця Т і зміщення сегменту ST вище ізолінії, що свідчить про ішемію міокарда та зниження його скоротливості (рис. 1, табл. 1).

У тварин, що отримували комбінацію АТФ-ЛОНГ молсидоміну, порушення ритму серця не зареєстровані, а частота скорочень серця не відрізнялась від інтактних тварин (див. рис. 1 і табл. 1).

На електрокардіограмі у тварин цієї групи відмічаються позитивні зміни в порівнянні з контрольною групою, які свідчать про покращення скоротливості міокарда зменшення депресії зубця R, нормалізація зубця T, не зареєстровано зміщення сегменту ST від ізолінії, що можна пояснити цитопротекторною дією препарату, покращенням постачання кисню до міокарда та відновленням енергетичного балансу кардіоміоцитів.
У старих щурів реакція на психоемоційний стрес була більш виразною, ніж у молодих тварин (рис. 2, табл. 2).

Порушення ритму серця у старих щурів проявлялося переважно тахі- або брадикардією. Поряд 3 цим відмічалося збільшення інтервалу PQ і розширення комплексу QRS, що свідчить про порушення атріовентрикулярної провідності.

Про зниження скорочувальної здатності міокарда у старих тварин свідчить зниження амплітуди зубця R i поява глибокого зубця S у II відведенні, який у щурів звичайно реєструється тільки у 10-20\% випадків. Спостерігалась інверсія зубця Т і підвищення сегменту ST, у деяких щурів не реєструвався зубець Р.

У старих щурів, які одержували комбінацію АТФЛОНГ і молсидоміну, спостерігалась позитивна динаміка електрофізіологічних параметрів міокарда (див. рис. 2 і табл. 2). Після введення препарату у дослідних щурів сповільнювалась депресія зубця $\mathrm{R}$, величина якого була на рівні 0,62 mV, що становило $91 \%$ від вольтажу тварин інтактної групи, та була вірогідно вищою, ніж у контрольній групі. На ЕКГ не було виявлено появи та поглиблення зубця S, сегмент ST не підіймався над ізолінією, не було зареєстровано розширення комплексу QRS та значущого збільшення тривалості інтервалу Q-T. У щурів цієї групи була відсутня вірогідна різниця з параметрами ЕКГ тварин інтактної групи.

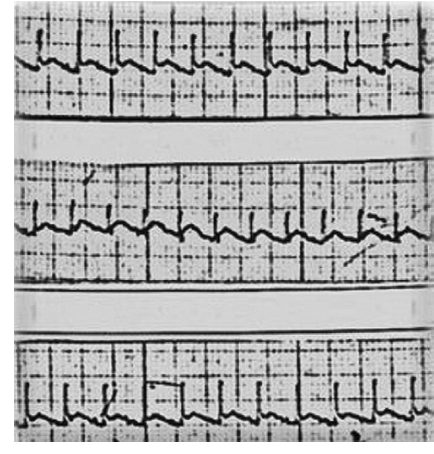

A

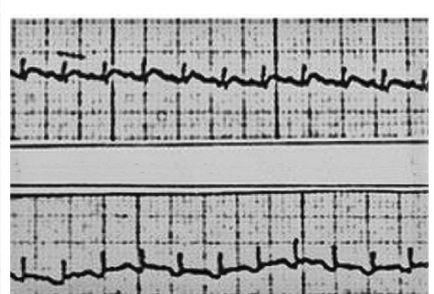

B

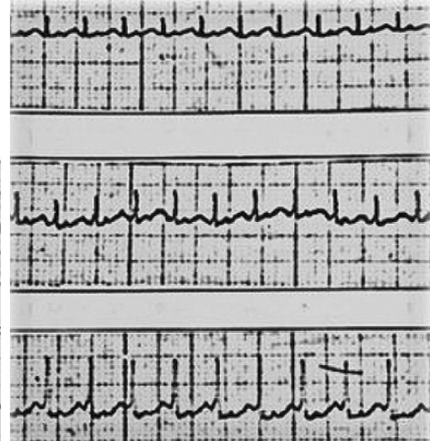

C

ТАБЛИЦЯ 1 / ТАВLE 1

ВПЛИВ КОМБІНАЦІЇ АТФ-ЛОНГ І МОЛСИДОМІНУ НА ПОКАЗНИКИ БІОЕЛЕКТРИЧНОЇ АКТИВНОСТІ СЕРЦЯ МОЛОДИХ ЩУРІВ ЗІ СТРЕСОМ / EFFECT OF THE COMBINATION OF ATP-LONG AND MOLSIDOMINE ON THE BIOELECTRICAL ACTIVITY PARAMETERS OF THE HEART OF YOUNG RATS WITH STRESS

\begin{tabular}{|l|c|c|c}
\multicolumn{1}{|c|}{ Показники ЕКГ / ECG indicators } & $\begin{array}{c}\text { Iнтактна група / } \\
\text { Intact group }\end{array}$ & $\begin{array}{c}\text { Контрольна група / } \\
\text { Control group }\end{array}$ & $\begin{array}{c}\text { Дослідна група / } \\
\text { Experimental group }\end{array}$ \\
\hline ЧСС (уд/хв) / Неart rate, beats/min & $485,9 \pm 1,1$ & $516 \pm 1,8^{*}$ & $490,5 \pm 1,2^{* *}$ \\
\hline Амплітуда зубця R (мB) / Wave amplitude R, mV & $0,76 \pm 0,05$ & $0,28 \pm 0,02^{*}$ & $0,65 \pm 0,08^{* *}$ \\
\hline Амплітуда зубця P (MB) / Wave amplitude P, mV & $0,11 \pm 0,03$ & $0,08 \pm 0,04$ & $0,10 \pm 0,02$ \\
\hline Амплітуда зубця T (MB) / Wave amplitude T, mV & $0,21 \pm 0,04$ & $0,26 \pm 0,04$ & $0,18 \pm 0,04$ \\
\hline Довжина інтервалу R-R (MC) / Interval length R-R, mS & $123,5 \pm 0,3$ & $117,00 \pm 0,08^{*}$ & $122,3 \pm 0,4$ \\
\hline Довжина комплексу QRS (Mc) / Complex length QRS, mS & $20,7 \pm 0,2$ & $26,0 \pm 0,5^{*}$ & $21,3 \pm 0,2^{* *}$ \\
\hline Довжина інтервалу Q-T (Мс) / Interval length Q-T, mS & $71,7 \pm 0,2$ & $69,5 \pm 0,4$ & $70,5 \pm 0,3$
\end{tabular}

Примітки / Note: * - p <0,05 - порівняно з показниками інтактної групи; ** $-p<0,05$ - порівняно з показниками контрольної групи / * $-p<0.05-$ compared with indicators of intact group; ${ }^{* *}-p<0.05$ - compared with indicators of control group. 


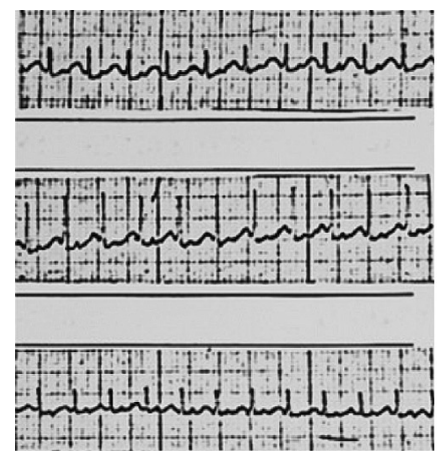

A

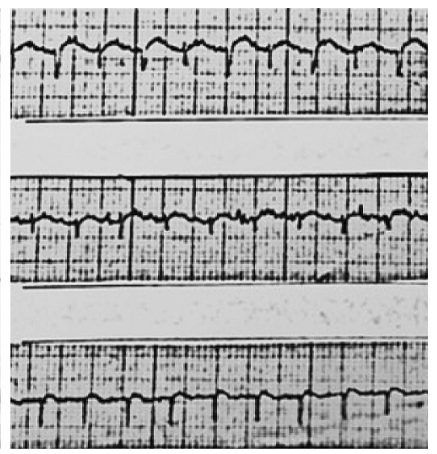

B

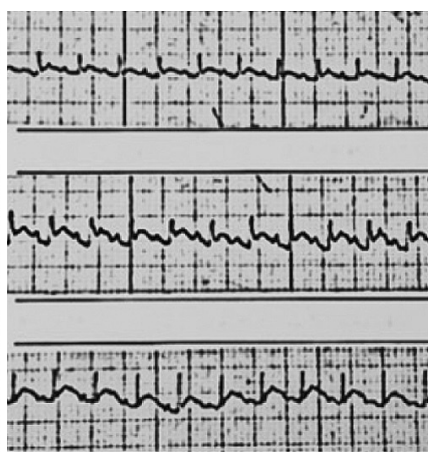

C
Рис. 2 / Fig. 2. Електрокардіограми старих щурів (А інтактні щури, В - щури з хронічним стресом, С - щури 3 хронічним стресом, які отримували комплекс АТФ-ЛОНГ і молсидоміну) / Electrocardiograms of old rats (A - intact rats, B - rats with chronic stress, C rats with chronic stress treated with a combination of ATP-LONG and molsidomine).

ТАБЛИЦЯ 2 / TAВLE 2

ВПЛИВ КОМБІНАЦІЇ АТФ-ЛОНГ І МОЛСИДОМІНУ НА ПОКАЗНИКИ БІОЕЛЕКТРИЧНОЇ АКТИВНОСТІ СЕРЦЯ

СТАРИХ ЩУРIВ 3І СТРЕСОM / EFFECT OF THE COMBINATION OF ATP-LONG AND MOLSIDOMINE ON THE BIOELECTRICAL ACTIVITY PARAMETERS OF THE HEART OF OLD RATS WITH STRESS

\begin{tabular}{|l|c|c|c|}
\multicolumn{1}{c|}{ Показники ЕКГ / ECG indicators } & $\begin{array}{c}\text { Iнтактна група / } \\
\text { Intact group }\end{array}$ & $\begin{array}{c}\text { Контрольна група / } \\
\text { Control group }\end{array}$ & $\begin{array}{c}\text { Дослідна група / } \\
\text { Experimental group }\end{array}$ \\
\hline ЧСС (уд/хв) / Heart rate, beats/min & $432,8 \pm 4,3$ & $456,5 \pm 1,9^{*}$ & $428,6 \pm 1,3^{* *}$ \\
\hline Амплітуда зубця R (мB) / Wave amplitude R, mV & $0,68 \pm 0,07$ & $0,11 \pm 0,05^{*}$ & $0,62 \pm 0,04^{* *}$ \\
\hline Амплітуда зубця S (мB) / Wave amplitude S, mV & відсутній & $0,52 \pm 0,06$ & відсутній \\
\hline Амплітуда зубця P (MB) / Wave amplitude P, mV & $0,12 \pm 0,04$ & $0,11 \pm 0,04$ & $0,12 \pm 0,04$ \\
\hline Амплітуда зубця T (мB) / Wave amplitude T, mV & $0,18 \pm 0,04$ & $0,19 \pm 0,03$ & $0,16 \pm 0,03$ \\
\hline Довжина інтервалу R-R (Mc) / Interval length R-R, mS & $138,7 \pm 1,3$ & $131,3 \pm 0,6^{*}$ & $140,0 \pm 0,4$ \\
\hline Довжина комплексу QRS (MC) / Complex length QRS, mS & $20,3 \pm 0,2$ & $25,0 \pm 1,5^{*}$ & $20,3 \pm 0,2^{* *}$ \\
\hline Довжина інтервалу Q-T (мс) / Interval length Q-T, mS & $71,2 \pm 0,1$ & $68,7 \pm 1,1^{*}$ & $70,3 \pm 0,2^{* *}$ \\
\hline
\end{tabular}

Примітки / Note: * $-p<0,05$ - порівняно з показниками інтактної групи; ** $-p<0,05-$ порівняно з показниками контрольної групи / * - < 0.05 compared with indicators of intact group; ** $-p<0.05$ - compared with indicators of control group.

Результати проведених досліджень свідчать, що курсове введення комбінації АТФ-ЛОНГ і молсидоміну зменшувало шкідливий вплив хронічного м'якого стресу на серце як молодих, так і старих щурів. Кардіопротекторна дія комбінації виявлялась нормалізацією показників ЕКГ, порушених під дією стресу.

АТФ-ЛОНГ виступає як стимулятор енергетичного обміну в кардіоміоцитах, підвищує активність мембранних іонних каналів шляхом взаємодії з пуринергічними рецепторами; в умовах ішемізації міокарда зменшує його потребу в кисні шляхом участі в метаболічних процесах.

Молсидомін, як донатор оксиду азоту, покращує перфузію у системі коронарних артерій внаслідок вазодилататорного ефекту, оптимізує метаболічні процеси в умовах хронічного стресу і запобігає обумовленому стресом пошкодженню клітинних мембран.

Аддитивна дія компонентів забезпечує кардіопротекторну дію комбінації АТФ-ЛОНГ і молсидоміну в умовах хронічного м'якого стресу.

\section{ВИСНОВКИ}

1 Вивчено кардіопротекторну дію комбінації АТФ1 ЛОНГ і молсидоміну на молодих і старих щурах в умовах хронічного м'якого стресу.

2 у молодих щурів встановлена негативна дія хроніч2 ного м'якого стресу на біоелектричну активність міокарда - порушення процесів реполяризації, проведення i скоротливості серця. Введення комбінації АТФ-ЛОНГ і молсидоміну нормалізувало показники біоелектричної активності міокарда та підвищувало його стійкість до дії стресувальних факторів.

2 У старих щурів під дією хронічного м'якого стресу $\mathcal{3}$ ознаки порушення реполяризації та електричної нестабільності серця були більш значними в порівнянні з молодими тваринами. Застосування комбінації АТФ-ЛОНГ і молсидоміну запобігало пошкоджувальному впливу хронічного стресу та сприяло нормалізації електрофізіологічних параметрів міокарда старих щурів.

$\triangle$ Результати експериментальних досліджень свідчать Еро фармакологічну кардіотропну активність комбінації АТФ-ЛОНГ і молсидоміну у молодих і старих щурів. 
1. Chebotarev DF. [Geriatrics in the clinic of internal medicine]. Kiev: Zdorovya, 1997. 304 p. Russian.

2. Korkushko OV, Chebotaryov DF, Kolinkovsky VG. [Geriatrics in therapeutic practice]. Kyiv: Zdorovya, 1993. 840 p. Ukrainian.

3. Frolkis VV, Bezrukov VV, Shevchuk VG; Chebotaryov DF, editor [Circulation and Aging]. Leningrad.: Nauka; 1984. 216 p. Russian.

4. Korkushko OV, Yaroshenko YuT. [Reserve capacities of main functions of cardiovascular system during aging (review of literature and own data)]. Problems of Aging and Longevity. 2012;21(2):119-52. Russian.

5. Kraynak TE, Marsland AL, Gianaros PJ. Neural mechanisms linking emotion with cardiovascular disease. Curr Cardiol Rep. 2018 Oct 11;20(12):128. DOI: 10.1007/s11886- 018-1071-y.

6. Nikolaev EL. Lazareva EY. [Psychosocial risks and resources in cardiovascular disease]. Journal of Psychiatry and Psychology of Chuvashia. 2014;10:109-30. Russian.

7. Meerson FZ. [Pathogenesis and prevention of stress and ischemic heart damage]. Moscow.: Meditsina; 1984. 270 p. Russian.

8. Saul Al, Meerson FZ. [Post-stress myocardial dysfunction]. Chisinau: Shtinitsa; 1990. 161 p. Russian.

9. Golbidi S, Frisbee JC, Laher I. Chronic stress impacts the cardiovascular system: animal models and clinical outcomes. Am J Physiol Heart Circ Physiol. 2015 Jun 15;308(12):H1476-98. DOI: 10.1152/ajpheart.00859.2014.

10. Bergh $C$, Udumyan $R$, Fall $K$, Almroth $H$ Montgomery $S$. Stress resilience and physical fitness in adolescence and risk of coronary heart disease in middle age. Heart. 2015 Apr;101(8):623-9.

DOI: 10.1136/heartjnl-2014-306703.

11. Ziegelstein $R C$. Acute emotional stress and cardiac arrhythmias. JAMA. 2007 Jul 18;298(3):324-9. DOI: 10.1001/jama.298.3.324.

12. Gianni $M$, Dentali F, Grandi $A M$, Sumner $G$, Hiralal R, Lonn E. Apical ballooning syndrome or takotsubo cardiomyopathy: a systematic review. Eur Heart J. 2006 Jul;27(13):1523-9.

DOI: 10.1093/eurheartj/ehl032.

13. McEwen BS. Neurobiological and systemic effects of chronic stress. Chronic Stress (Thousand Oaks). 2017 JanDec;1:2470547017692328.

DOI: $10.1177 / 2470547017692328$.

14. Mayorov OY. [Quantitative assessment of stress and ischemic myocardial damage in normal and in conditions of emotional stress modeling in the experiment: a factor model]. Clinical informatics and telemedicine. 2013;9(10):13-4. Russian

15. Todorov II, Todorov GI. [Stress, aging and their biochemical correction]. Moscow: Nauka; 2003. 479 p. Russian.

16. Frolkis VV. [Stress-Age-Syndrome]. Physiological Journal. 1991;3:3-10. Russian.

17. Kirichek $L T$, Shcherban NG. [Metabolic and metabolitotropic drugs in the system of stress protection]. Mezhdunar. med. zhurnal. 2012;2:103-8. Russian.

18. Vizier VR, Voloshin IN, Voloshin NA et al. [Metabolic cardioprotectors: pharmacological properties and application in clinical practice] Zaporozhye: Zaporozhye State University; 2006. 36 p. Russian.

19. Amosova EN. [Metabolic therapy of myocardial damage due to ischemia. A new approach to the treatment of coronary heart disease and heart failure]. Ukrainian Journal of Cardiology. 2000;4:86-92. Ukrainian.

20. Zhigunova AK. [Cardioprotective drug ATPlong and its effect on metabolic processes in the myocardium]. Ukrainian Medical Journal. 2012;3(89):65-71. Russian.

21. Amosova EN, Bereza NV, Potapkova IV. [The effect of complex therapy with the inclusion of ATP-LONG on the diastolic function of the left ventricle in patients with coronary heart disease at rest and under isometric load]. Medical business. 2002;(3-4):48-50. Russian.

22. Lipkan G, Mkhitaryn L, Kutnyak V. [ATP-long representative of the new class of cardiotropic drugs]. Journal of practical doctor. 1999;4:56-9. Russian.

23. Denisyuk V, Lipnitsky T, Sizova M et al. [Increased efficiency antiarrythmic and antianginal a drugs when combined with ATPlong in sick IHD elderly and old age]. Cardiac arrhythmias: age aspects: Materials of the 1st Ukrainian scientific-practical conference with international participation. Kyiv; 2000. P. 55-8. Russian.

24. Chistik T. [Nitric oxide donors in the treatment of cardiovascular pathology: nitrates or sidnonamines?] Medicine and pharmacy news. 2014;1-2:485-7. Russian

25. Vertkin A, Toholiansky A. [Molsidomin - new perspectives]. RMJ. 2004;12(5):364-6. Russian.

26. Barbato E, Herman A, Benit E, Janssens L Lalmand J, Hoffer E et al. Long-term effect of molsidomine, a direct nitric oxide donor, as an addon treatment, on endothelial dysfunction in patients with stable angina pectoris undergoing percutaneous coronary intervention: results of the MEDCOR trial. Atherosclerosis. 2015 Jun;240(2):3514. DOI: 10.1016/j.atherosclerosis.2015.03.045.

27. Wöhrle J, Nusser T, Hoffmeister A, Kestler HA Grebe OC, Höher M et al. Einfluss von Molsidomin auf rheologische Parameter und die Inzidenz kardiovaskulärer Ereignisse [Effect of molsidomine on rheological parameters and the incidence of cardiovascular events]. Dtsch Med Wochenschr. 2003 Jun 13;128(24):1333-7. German. DOI: 10.1055/s-2003-39973.

28. Messin R, Dubois C, Famaey JP. Comparative effects of once-daily molsidomine in coronary patients from two distinct European ethnicities. Adv Ther. 2008 Nov;25(11):1200-14.

DOI: $10.1007 / \mathrm{s} 12325-008-0117-8$.

29. Willner P. Validity, rehabilitee and utility of the chronic mild stress model of depression: a 10-year review and evaluation.

Psychopharmacology (Berl.). 1997 Dec;134(4):319-29. DOI: 10.1007/s002130050456.

30. Krupina NA, Khlebnikova NN, Orlova IN [Effects of chronic mild stress in Wistar and August rats: behavior and content of monoamines in the striatum]. Pathogenesis. 2012;10(2):50-8. Russian. 
ВАияние комбинации АТФ-АОНГ и молсидомина на биоэлектрическую активность миокарда молодых и старых крыс в условиях хронического мягкого стресса

\section{Л. П. Купраш , Л. Б. Шарабура, \\ Т. М. Пантелеймонова, С. А. Гударенко, Н. В. Сикало, В. В. Безруков}

ГУ «Институт геронтологии им. Д. Ф. Чеботарева НАМН Украинь», ул. Выцигородская, 69, Киев 04114, Украина

Введение. Возрастные изменения сердечно-сосудистой системы обусловливают снижение ее резервных адаптационных возможностей и повышение вероятности развития заболеваний в условиях стресса и нагрузки. В ряде исследований доказана значительная роль эмоционального перенапряжения и стрессов в развитии сердечно-сосудистых заболеваний. Высокий уровень заболеваемости системы кровообращения, длительное течение и тяжесть заболеваний у людей пожилого и старческого возраста определяют актуальность поиска для лечения с использованием эффективных и безопасных лекарственных средств.

Цель работы: изучить влияние комбинации АТФ-ЛОНГ и молсидомина на функциональное состояние миокарда молодых и старых крыс в условиях хронического мягкого стресса.

Материалы и методы. В опытах на молодых (10 мес.) и старых (24 мес.) крысах-самцах линии Wistar исследована кардиотропная и кардиопротекторная активность комбинации метаболического кардиопротектора АТФ-ЛОНГ и сосудорасширяющего средства молсидомина в условиях хронического мягкого стресса.
Результаты. У молодых крыс установлено негативное воздействие хронического мягкого стресса на биоэлекрическую активность миокарда - нарушение процессов реполяризации, проводимости и сократимости сердца. Введение комбинации АТФЛОНГ и молсидомина нормализовало показатели биоэлектрической активности миокарда и повышало его устойчивость к действию стрессовых факторов. У старых крыс под действием хронического стресса признаки нарушения реполяризации и электрической нестабильности сердца были более значительными по сравнению с молодыми животными. Применение комбинации АТФ-ЛОНГ и молсидомина предотвращало повреждающее влияние хронического стресса и способствовало нормализации электрофизиологических параметров миокарда старых крыс.

Выводы. Результаты экспериментальных исследований свидетельствуют о фармакологической кардиотропной активности комбинации АТФ-ЛОНГ и молсидомина у молодых и старых крыс в условиях хронического мягкого стресса.

Ключевые слова: молодые крысы, старые крысы, хронический мягкий стресс, миокард, электрокардиограмма, биоэлектрическая активность сердца, АТФ-лонг, молсидомин, кардиопротекторное действие.

Для цитирования: Купраш ЛП, Шарабура ЛБ, ПантелеймоноватМ, Сикало НВ, Безруков ВВ. Влияние комбинации АТФ-ЛОНГ и молсидомина на биоэлектрическую активность миокарда молодых и старих крыс при условии хронического мягкого стресса. Журнал Национальной академии медицинских наук Украины. 2021;27(1):5-11. DOI: 10.37621/JNAMSU-2021-1-1.

Статья поступила в редакцию 22.12.2020| Направлена на рецензирование 24.02.2021 | Принята в печать 28.04.2021 